\title{
Accessibility and the evaluation of investments on the Beijing subway
}

\author{
Haibing Jiang \\ University of Minnesota \\ haibingjiang1@163.com
}

\author{
David Levinson \\ University of Minnesota \\ dlevinson@umn.edu
}

\begin{abstract}
This study measures the job and population accessibility via transit for Beijing using the cumulative opportunity metric. It is shown that transit accessibility varies widely across Beijing, but is highly focused on subway stations. Early lines added far more accessibility than more recently planned lines.
\end{abstract}

\author{
Article History: \\ Received: January 26, \\ 2016 \\ Accepted: March 29, \\ 2016 \\ Available online: December 27, 2016
}

\section{Introduction}

This research note explores Beijing's relationship between the physical infrastructure (subway), land use (population and job density), and accessibility - a measure of the ease of reaching destinations by public transit. Beijing makes an interesting case because of its rapidly changing nature, comparable with the change in rapidly urbanizing western cities in the late 19th and early 20th centuries. In contrast with those cities however, subways in China are following a systematic transportation plan, rather than being the investments of entrepreneurs. It has been shown that in London, the entrepreneurs, with government oversight, made reasonable investments that generally increased accessibility more than the unchosen alternatives (Levinson et al. 2015). Here we compare the investments over time.

China's capital Beijing has a 2014 population of over 21 million, with more than 12 million people and more than 9000 people per $\mathrm{km}^{2}$ in the core urban zone. The urbanized area of Beijing increased by half in just over a decade from $1043 \mathrm{~km}^{2}$ in 2002 to $1586 \mathrm{~km}^{2}$ in 2014, and the commute time between job and home increased dramatically, which now reportedly averages 52 minutes (Niu 2012).

The Beijing Subway network (Figure 1) expanded dramatically from 2 subway lines with a total length of $54 \mathrm{~km}$ in 2000 to 18 lines with a total length $527 \mathrm{~km}$ as of 2015. It is now the world's busiest in annual ridership, with 3.41 billion trips delivered in 2014, averaging 9.28 million per day, with peak single-day ridership reaching 11.56 million. In addition, there were 877 bus lines running $202,500 \mathrm{~km}$ daily in 2014.

Over the same period, the share of subway riders in public transit drastically increased, especially since 2008. In 1999 only $11.3 \%$ of transit riders used the subway. However, by 2014 the share of subway riders exceeded 40\%. In 2014, transit overall achieved a 48\% mode share of travel in the Beijing urban core (China Economic Net news 2014; China Quality Daily 2014).

Copyright 2016 Haibing Jiang and David Levinson.

doi: $10.5198 /$ jtlu.2016.884

ISSN: 1938-7849 | Licensed under the Creative Commons Attribution - NonCommercial License 3.0.

The Journal of Transport and Land Use is the official journal of the World Society for Transport and Land Use (WSTLUR) and is published and sponsored by the University of Minnesota Center for Transportation Studies. 
This study computes population accessibility via transit (using walk access and egress) in Beijing for 2000 and 2010, job accessibility in 2013, and correlates the expansion of the network with accessibility. By examining the contribution of each individual Subway Line, the cost effectiveness of routes can be ascertained, which may help future planning. This study complements previous research by the author and others on transit networks development and land use change (Block-Schachter and Zhao 2015; King 2011; Levinson 2008; Levinson et al. 2015; Xie and Levinson 2009).

Sections 2, 3, 4, and 5 discuss the Data, Methods, Results, and Conclusions in turn.

\section{Data}

The Beijing urban zone within the Sixth Ring Road comprises the study area. Beijing is divided into Jiedao (meaning 'subdistrict' in Chinese), the basic administrative unit in Chinese cities and the lowest geographic level reported in publicly accessible government statistical reports. This study uses three classes of data: land use, population and employment, and network data, which are described in turn.

\subsection{Land use data}

Land use data came from the 2004 Land Use GIS database maintained by the Beijing Urban Planning Department. We select the 7540 residence polygons and 9279 employment polygons within the Sixth Ring Road. In order to generate a finer resolution accessibility map, we choose a 200-meter grid (each cell is $40,000 \mathrm{~m}^{2}$ ), resulting in 57,625 grid cells, and created centroids for each cell. If we were to choose the Jiedao centroid level, the accessibility maps would have coarse resolution. On average this disaggregated presentation and analysis better reflects the spatial distribution of activity than assuming a uniform value across the Jiedao.

\subsection{Population and employment data}

Population data were obtained for the 178 current Jiedao administrative districts inside the Sixth Ring Road, from the 2000 and 2010 national population Census. The population in other years is linearly interpolated or extrapolated. Employment data in 2013 by local authority are available from the third China National Economic Census.

The population and employment data at the parcel or other local land use area were unavailable, so the research team distributed the 178 Jiedao population and employee data into the residential and employment polygons according to the land use data and assuming uniform density within residential polygons in each Jiedao, and similarly, uniform employment density for employment polygons within each Jiedao.

$$
P_{i}=\frac{k_{i}}{k_{B}} P_{B}
$$

where $k_{B}=$ the residential land use areas of Jiedao $B$,

$k_{i}$ is the area of residential cell $i$.

$P_{B}$ is the population of Jiedao $B$.

From these $P_{i}$ is obtained, the population within cell $i$.

$$
E_{i}=\frac{l_{i}}{l_{B}} E_{B}
$$

where $l_{B}=$ the employment land use areas of Jiedao $B$,

$l_{i}$ is the area of employment cell $i$.

$E_{B}$ is the employment of Jiedao $B$.

From these $E_{i}$ is obtained, the employment within cell $i$. 
Table 1: Subway speed and headway in Beijing

\begin{tabular}{lrr}
\hline Name & Speed $(\mathrm{km} / \mathrm{h})$ & Headway $(\mathrm{min})$ \\
\hline Subway 1 & 31.89 & 4 \\
Subway 2 & 30.63 & 4 \\
Subway 3 & 32.22 & 4 \\
Subway 5 & 30.91 & 4 \\
Subway 6 & 33.63 & 5 \\
Subway 7 & 30.95 & 5 \\
Subway 8 & 33.32 & 7 \\
Subway 9 & 31.20 & 6 \\
Subway 10 & 30.48 & 4 \\
Subway 13 & 36.00 & 4 \\
Subway 14 & 33.60 & 8 \\
Subway 15 & 35.91 & 7 \\
Subway Changping & 37.41 & 7 \\
Subway Fangshan & 35.38 & 7 \\
Subway Airport & 66.95 & 10 \\
Subway Yizhuang & 33.54 & 7 \\
Subway Batong & 31.94 & 4 \\
\hline
\end{tabular}

Note: Speed and headway are consistent through most of the day.

\subsection{Urban transport network data}

The urban transit network in this article includes the 1,543 bus transit routes and 42,161 bus stop points in 2013, 18 subway lines and 310 subway stations as of January 1st, 2015, in shape file format. The bus lines and stops data have been provided by the Beijing City Lab (Beijing City Lab 2014). Data describing the pedestrian network and subway lines in Beijing metropolitan area were obtained from OpenStreetMap (retrieved on May 17, 2015).

The other transit attributes include the 18 different subway speeds and departure headway, which differ by line and are set according to the subway company website (Table 1). In addition Bus transit lines are set at $17 \mathrm{~km} / \mathrm{h}$ uniformly, departure headway is set to $10 \mathrm{~min}$, pedestrian speed is $4.5 \mathrm{~km} / \mathrm{h}$ according to Baidu map.

Two additional assumptions are made. First the residential and employment polygons remain unchanged from 2000 to 2014 . We use the same land use data. Therefore, all population (from a given year) is distributed within the residential land (from 2004). Similarly jobs (from a given year) are distributed within the employment land (from 2004). Second, owing to the unavailability of digitized bus network data before the study year (2013), buses are assumed to have the same network routes and speeds between 2000 and 2013, with a 10-minute headway. Bus transfer and waiting times are considered.

\section{Methods}

The Cumulative Opportunity Measure is a widely used and easily understood method to calculate accessibility (Ingram 1971; Vickerman 1974; Wachs and Kumagai 1973). It counts the number of opportunities (destinations) within a given travel time threshold using a certain transportation mode. 
For accessibility to jobs, the opportunity refers to the number of jobs. Hence, the cumulative opportunity measure for job accessibility is typically expressed as:

$$
A_{j o b, i}=\sum_{j} E_{j} f\left(C_{i j}\right)
$$

Access to population is similarly:

$$
\begin{gathered}
A_{p o p, i}=\sum_{j} P_{j} f\left(C_{i j}\right) \\
f\left(C_{i j}\right)= \begin{cases}1 & \text { if } C_{i j} \leq T \\
0 & \text { if } C_{i j}>T\end{cases}
\end{gathered}
$$

Where:

$A_{j o b, i}$ stands for the job accessibility of cell $i$,

$A_{p o p, i}$ stands for the population accessibility of cell $i$,

$C_{i j}$ stands for the shortest transit travel time between cell $i$ and cell $j$,

$T$ represents the travel time threshold. (Here 30 minutes)

The cumulative opportunity measure is a simple way to explain and calculate accessibility since its cost function is binary, which is determined by the predetermined time threshold and the cost. This measure of cumulative opportunity is calculated for each grid cell using the data described in Section 2.

\subsection{Person-weighted accessibility}

Person-weighted accessibility (PWA) computes an overall weighted average of the accessibility, where the weights the accessibility of many locations are the population of each. The primary benefit of PWA is that it reduces the analysis to one number, allowing for internetwork and intranetwork comparison. PWA to jobs is computed as

$$
A_{j o b, p w, T}=\sum_{i=1}^{I} A_{j o b, i, T} P_{i}
$$

and similarly PWA to population is:

$$
A_{p o p, p w, T}=\sum_{i=1}^{I} A_{p o p, i, T} P_{i}
$$

\subsection{Accessibility calculation procedure}

Shortest transit travel time calculations for each OD pair are performed using network analysis toolbox in ArcGIS software. The time of travel by transit is comprised of several components:

- the time of traveling from the origin to a bus stop or subway station,

- the time waiting for a vehicle (half the headway),

- the time on-board a transit vehicle,

- transfer access time

- transfer wait time, and

- time spent traveling from the final transit station to the destination.

Each of these components is modeled explicitly.

The accessibility analysis here is strictly time-based. Fares during the study period were heavily subsidized by the Beijing government, however new pricing schemes since 2014 have changed fares. Future research could address the influence of transit fares on accessibility (El-Geneidy et al. 2016). 
The PWA of the subway lines built before 2009 use the population of Jiedao in 2000 for computing PWA; for subway lines constructed after 2009, we apply the population of Jiedao in 2010.

\section{Results}

\subsection{Job and population accessibility}

The Jiedao districts with a high job density mainly concentrate north of Subway Line 1 between the 2nd and 4th Ring Roads as shown in Figure 2. Furthermore most of the districts outside of the 5th Ring Road have very low job density. It indicates that job opportunities are still predominantly in the urban core.

The Jiedao districts with a high population density mainly were located in the west area inside the 3rd Ring Road in 2000 (See Figures 3(a)-3(c)). However, the Jiedao districts with high population density mainly were located in the north and south area between 2nd and 4th Ring Roads in 2010. Great change in population density has taken place between the 4th and 6th Ring Roads between 2000 and 2010. Accordingly most employment opportunities still assemble within the core urban zone while population has spread outside. So employment and housing became increasingly detached.

Figure 4 shows that overall the area within the 4 th Ring Road has comparatively high accessibility and most of the north parts of this zone can reach more than 100,000 jobs in 30 minutes by walk and transit. There is comparatively less job accessibility outside the 4th Ring Road for there are fewer bus lines and employment opportunities. In addition, as expected the area within the highest job accessibility lies along the main subway stations in the urban core. To be clear, there are some large subcenters with a job accessibility of more than 25,000 outside the 5 th Ring Road. The job accessibility value decays with distance from subway stations.

Figure 5(b) shows overall population accessibility patterns in 2010 differ from the job accessibility pattern in important ways. Compared with job accessibility, population accessibility distributes more uniformly. Figure 5(b) also shows that the highest population accessibility value around the stations on Subway Lines 1, 2, 4, 5 and 10. The higher value of more than 75,000 extended out of the 5th Ring Road in 2010 compared with 2000 (Figure 5(a)). The greatest change occurs in the area closest to the subway stations within the 4th Ring Road and local areas outside of the 5th Ring Road, as shown in Figure 5. 


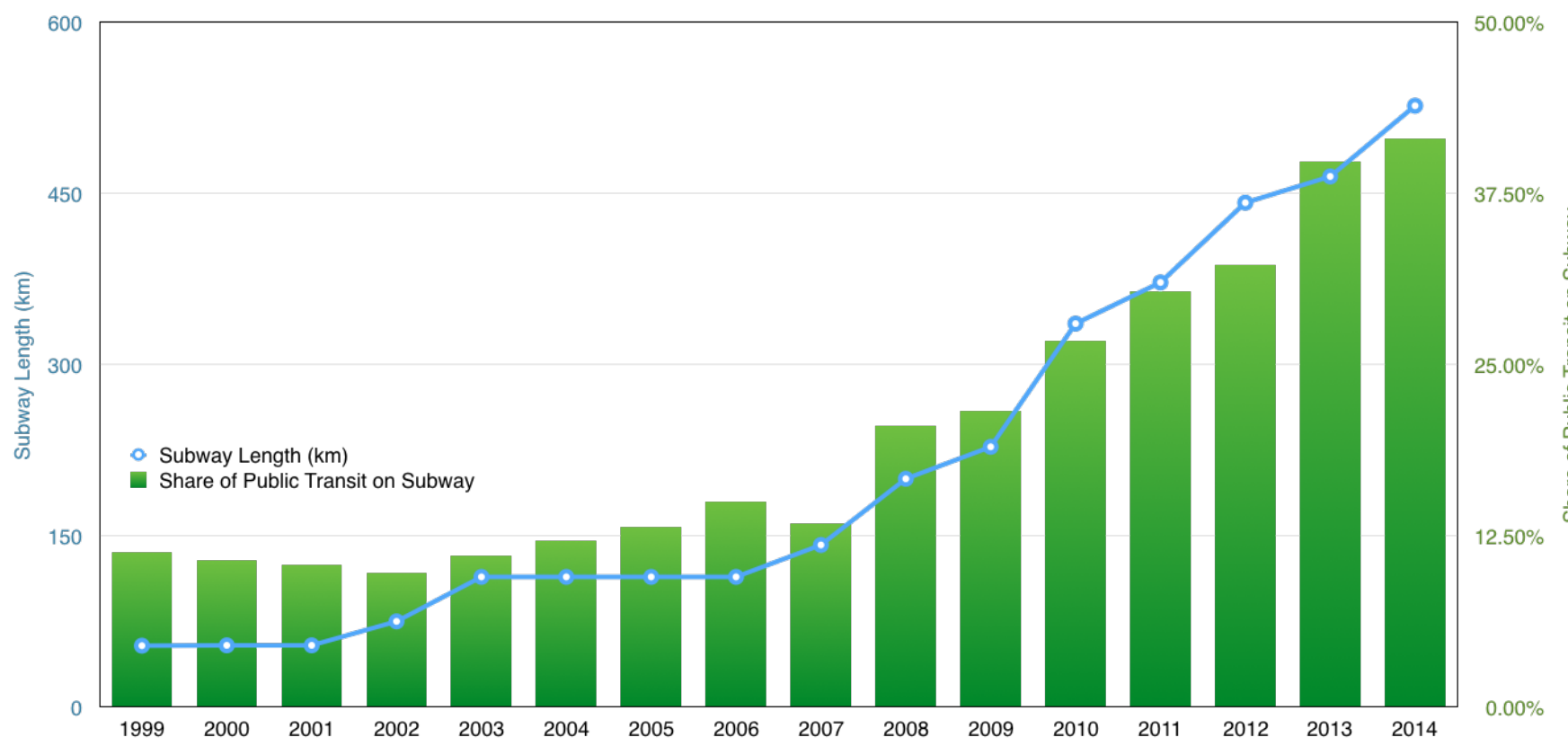

Figure 1: Share of public transit ridership on subways vs. Subway length

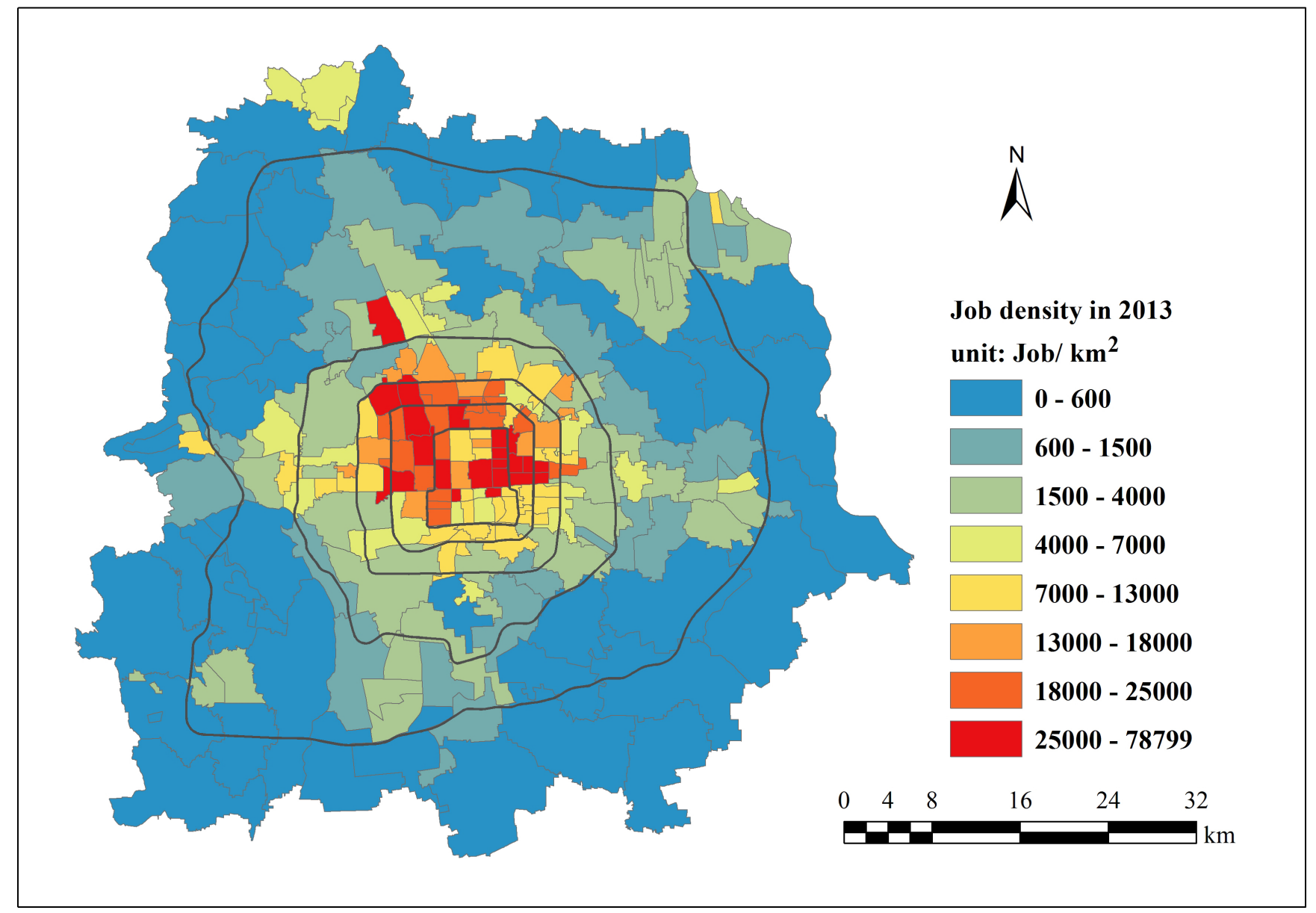

Figure 2: Employee opportunity density distribution in 2013 


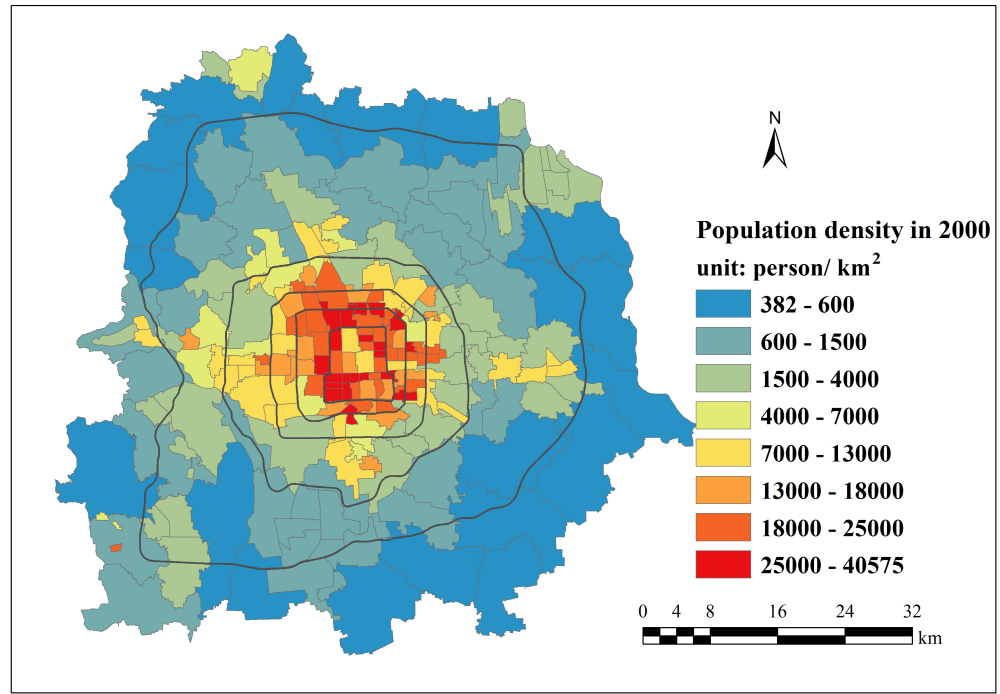

(a) 2000

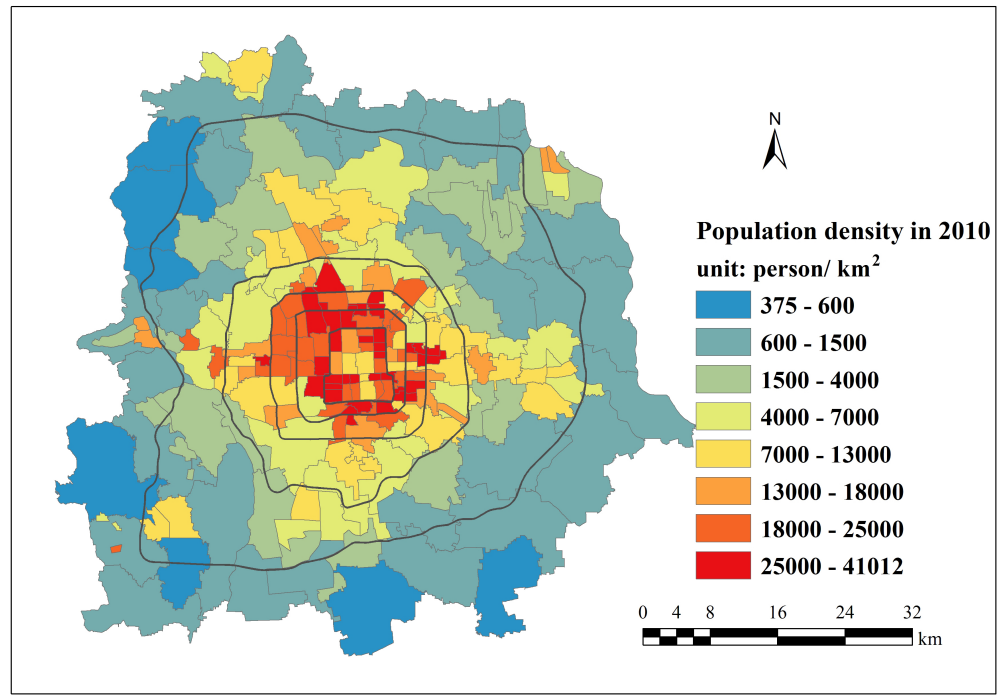

(b) 2010

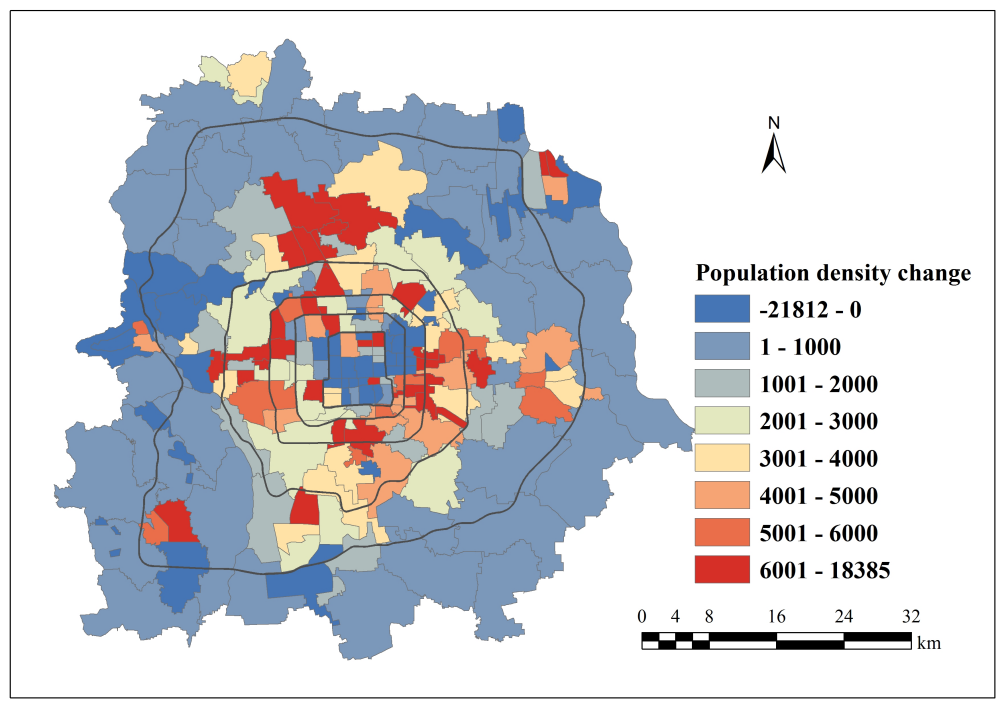

(c) $2010-2000$

Figure 3: Population density and change 


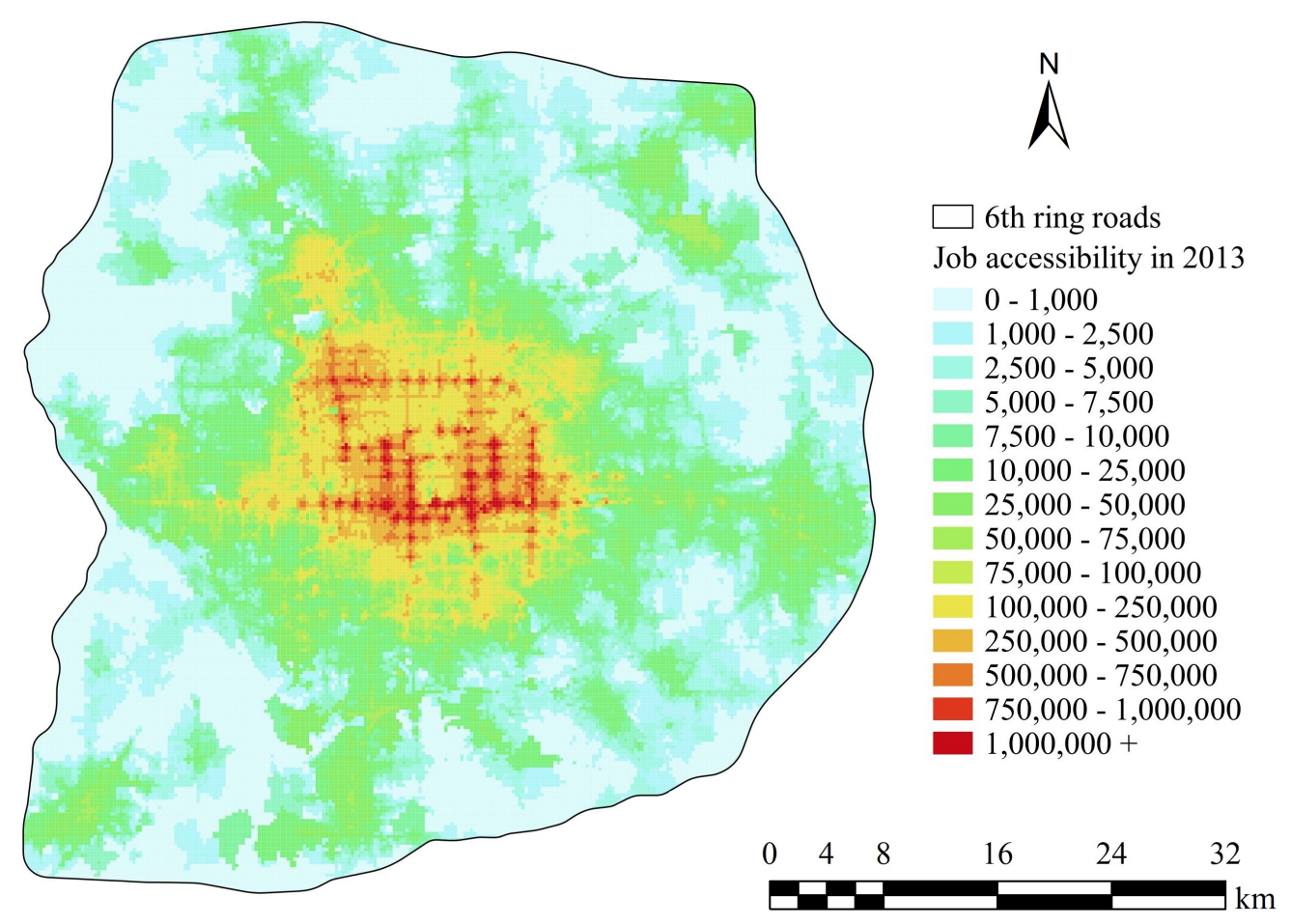

Figure 4: Job accessibility by transit in 2014 
Table 2: Person-weighted accessibility by subway line

\begin{tabular}{|c|c|c|c|c|c|}
\hline Name & Year & PWA $(E+12)$ & Change $(\mathrm{E}+8)$ & Length $(\mathrm{Km})$ & Efficiency $\left(\frac{\Delta P W A}{\Delta k m}\right)(\mathrm{E}+8)$ \\
\hline No subway & 1999 & 1.07887 & & & \\
\hline Subway 1 & 2000 & 1.14697 & 681 & 30.49 & 22.33 \\
\hline Subway 2 & 2002 & 1.27707 & 1301 & 23.31 & 55.82 \\
\hline Subway 13 & 2002 & 1.28807 & 110 & 41.02 & 2.68 \\
\hline Batong & 2003 & 1.30521 & 171 & 18.33 & 9.35 \\
\hline Subway 5 & 2007 & 1.46633 & 1611 & 28.07 & 57.4 \\
\hline Subway 8 & 2008 & 1.49574 & 294 & 25.51 & 11.53 \\
\hline Subway 10 & 2008 & 1.59799 & 1022 & 57.13 & 17.9 \\
\hline Jichang (Airport) & 2008 & 1.59834 & 3.48 & 27.88 & 0.124 \\
\hline Subway 4 & 2009 & 1.72569 & 1274 & 28.53 & 44.64 \\
\hline Subway 15 & 2010 & 1.76242 & 367 & 31.16 & 11.79 \\
\hline Changping & 2010 & 1.76242 & 0.0049 & 21.56 & 0.0002 \\
\hline Daxing & 2010 & 1.76282 & 4.03 & 22.17 & 0.18 \\
\hline Fangshan & 2010 & 1.76283 & 0.068 & 24.85 & 0.0027 \\
\hline Yizhuang: & 2010 & 1.76328 & 4.55 & 22.9 & 0.19 \\
\hline Subway 9 & 2011 & 1.81507 & 518 & 15.33 & 33.78 \\
\hline Subway 6 & 2012 & 1.90253 & 875 & 43.8 & 19.97 \\
\hline Subway 14 & 2013 & 1.9541 & 516 & 24.47 & 21.07 \\
\hline Subway 7 & 2014 & 2.04729 & 932 & 22.77 & 40.93 \\
\hline
\end{tabular}

\subsection{Subway line efficiency}

Figure 6 show that PWA increases between 2000 to 2010, from about 1.1E12 to about 1.8E12. As shown on Table 2, large changes in PWA occurs with the addition of subway lines 5, 2, 4, 10 in decreasing order. From the subway ridership perspective, it was basically stagnant from 1999 to 2003 at approximately 480 million trips. Between 2003 and 2008 it increased measurably, but the most remarkable increase in ridership begins in 2008. After 2008 it grew very fast from about 1,200 to 3,300 million trips in 2014. Ridership is linked to the development of subway lines through the production of accessibility.

While in general, subway lines have induced development, and development may attract subway investments, not all lines are created equal.

Turning to the question of efficiency of PWA, the subways of the urban core zone and outlying suburbs have an obvious efficiency gap shown in Figure 7. The subway lines to outlying suburbs such as the lines serving Changping, Fangshan, and Jichang have comparatively lower efficiency (PWA per km of line) value as shown. In contrast, the subway lines serving the urban core (Lines 2, 4 and 5) generally have higher efficiency values. Table 2 provides the numeric values of incremental accessibility, length, and efficiency associated with each subway line. The earliest planned lines (with lower numbers) are generally the most efficient. The more recent (named) lines are much less efficient, and are serving in many cases as yet undeveloped or underdeveloped greenfields.

\subsection{Regression model}

Results from the OLS regression models are presented in this section and summarized in tables 4, 5, and 6.

Model 1 (Table 3) and Model 2 (Table 4) show that change in population is positive and significantly correlated with number of subway stations. Similarly, accessibility to population is positively associated with change in number of stations. Because we only have one time period, it is not possible 


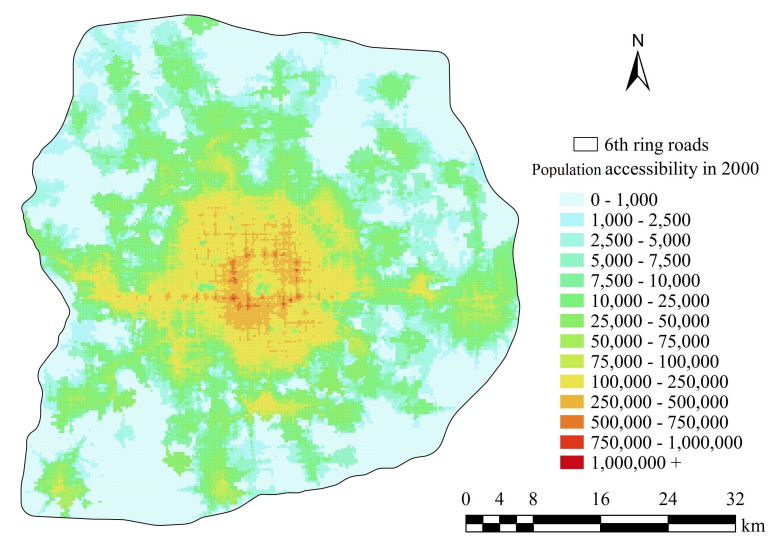

(a) 2000

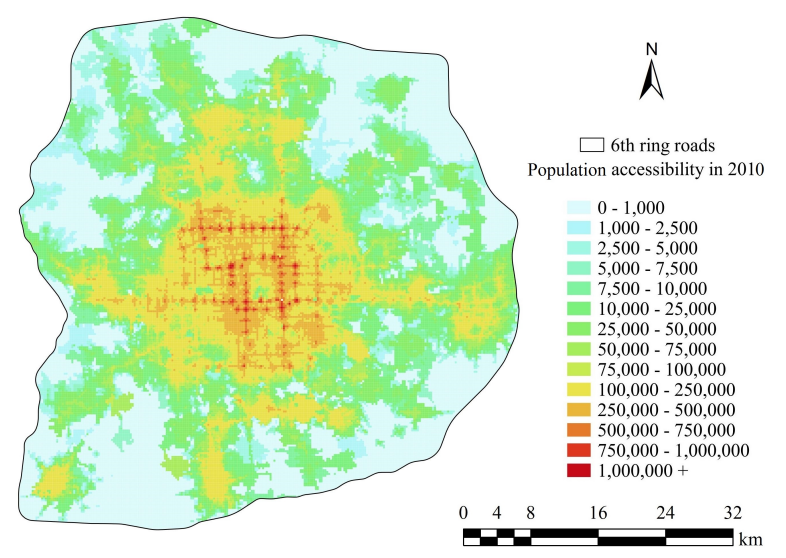

(b) 2010

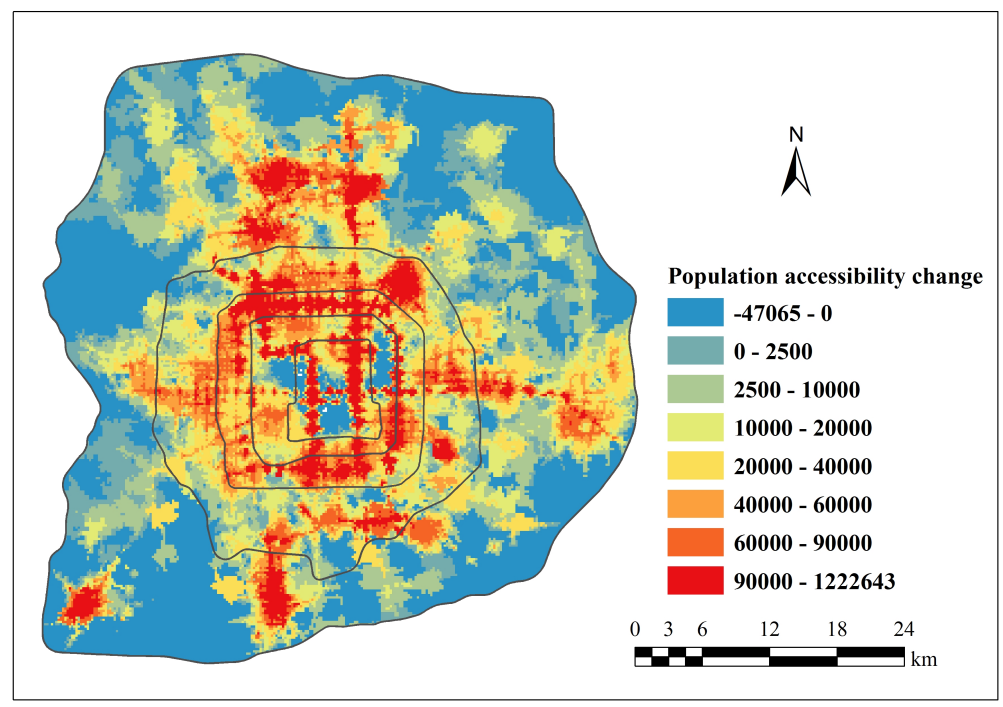

(c) $2010-2000$

Figure 5: Population accessibility and change 


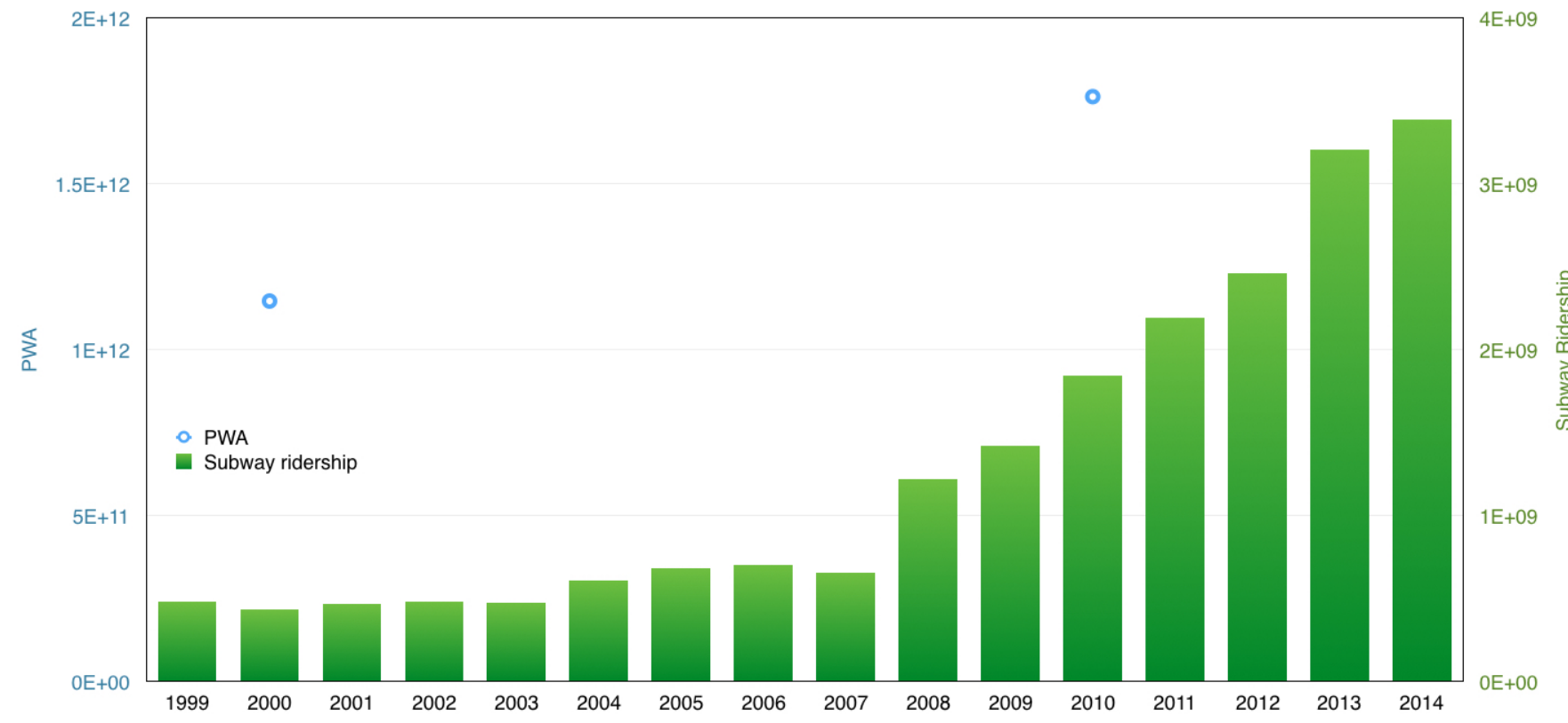

Figure 6: Observed person-weighted accessibility (PWA) versus annual passenger ridership over time

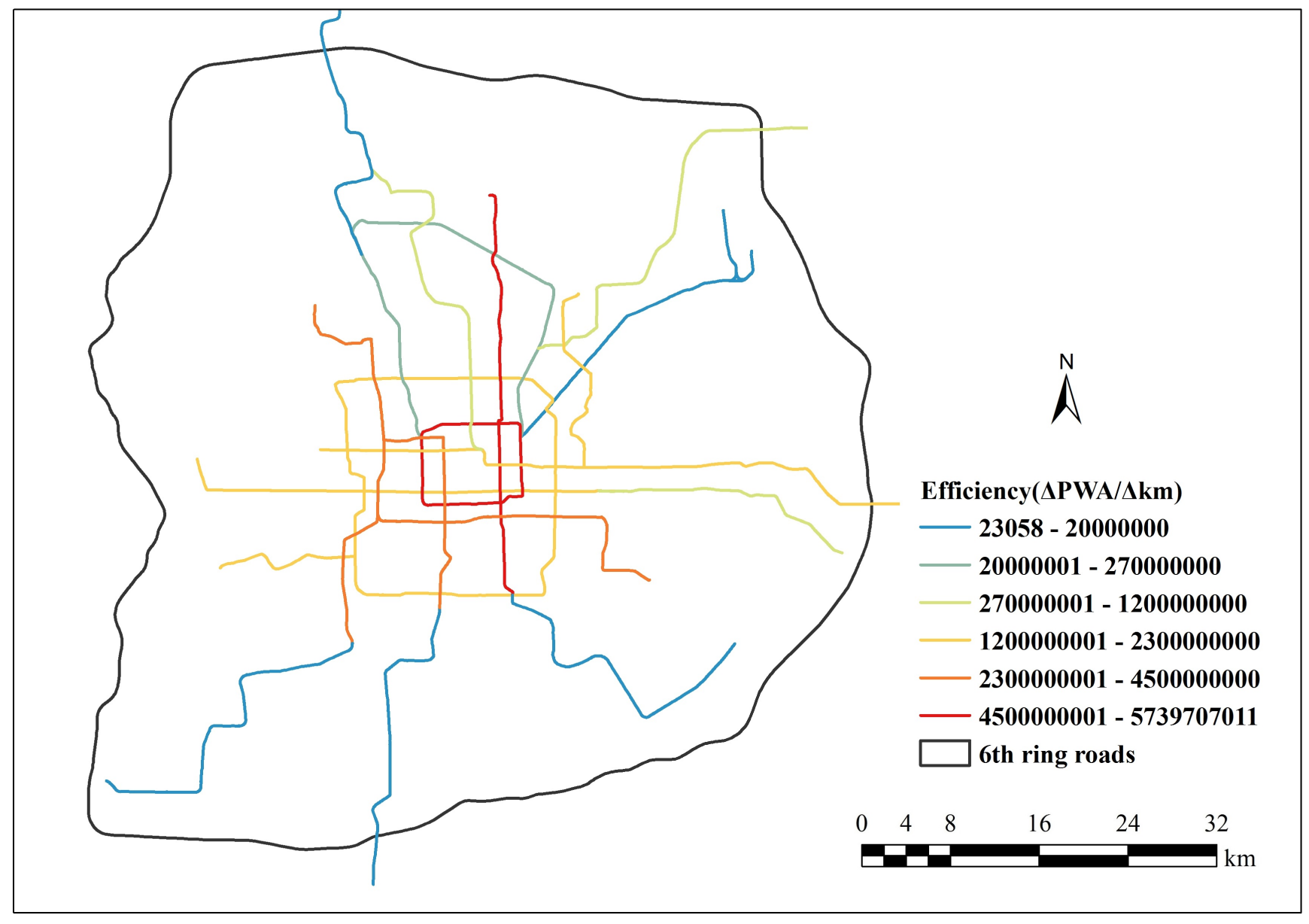

Figure 7: Subway line efficiency 
Table 3: Model 1: Number of Subway Stations (2010)

\begin{tabular}{lrrrr}
\hline & Coefficient & SE & $\mathrm{t}$ & Sig. \\
\hline Constant & 0.548 & 0.132 & 4.154 & .000 \\
Number of Stations in 2000 & 1.118 & 0.132 & 8.467 & .000 \\
Change in Population Accessibility (2010-2000) & $1.65 \mathrm{E}-05$ & .000 & 6.63 & .000 \\
Population Accessibility in 2000 & $-3.64 \mathrm{E}-06$ & .000 & -3.448 & .001 \\
\hline $\mathrm{N}$ & 178 & & & \\
$R^{2}$ & 0.403 & & & \\
\hline
\end{tabular}

Table 4: Model 2: Population accessibility (2010)

\begin{tabular}{lrrrr}
\hline & Coefficient & SE & $\mathrm{t}$ & Sig. \\
\hline Constant & 10311.565 & 3682.294 & 2.8 & .006 \\
Population Accessibility in 2000 & 1.217 & 0.022 & 54.52 & .000 \\
Change in Number of Stations (2010-2000) & 12163.607 & 1844.888 & 6.593 & .000 \\
\hline $\mathrm{N}$ & 178 & & & \\
$R^{2}$ & 0.945 & & & \\
\hline
\end{tabular}

to infer causality from these relationships, however the results are consistent with a positive feedback system (more population attracts more transportation investment, which increases accessibility, and attracts more population).

Model 3 (Table 5) shows that job accessibility is positively associated with number of stations, but negatively associated with population accessibility change, suggesting employers may be pricing residences out of certain areas, consistent with the case in London in the 19th century (Levinson 2008).

\section{Conclusions}

This research measured public transit accessibility in Beijing, and associated it with change in population and investment in new subway lines. It finds diminishing returns to subway investment, particularly new suburban lines, which produce far less accessibility (jobs reachable within 30 minutes) than do earlier more urban lines, after controlling for length of the lines. Lines to undeveloped, low density greenfields are logically more speculative than lines in already built up but underserved areas. Each line needs to be analyzed on its merits, and macro-economic notions of general infrastructure investment being valuable (Aschauer 1989), regardless of where it is applied, are misleading, even in relatively fast-growing economies like China. While it is too early to say whether China, like the US (Iacono and Levinson 2016), is yet a mature economy with regard to infrastructure, it is rapidly maturing, and faces the same general process of deployment, with large gains in lines designed in the early years, and fewer gains in the more recently planned subway lines serving unproven and speculative ar-

Table 5: Model 3: Jobs accessibility (2013)

\begin{tabular}{lrrrr}
\hline & Coefficient & SE & $\mathrm{t}$ & Sig. \\
\hline Constant & -34880.33 & 8895.808 & -3.921 & .000 \\
Population accessibility in 2010 & 1.539 & 0.064 & 23.869 & .000 \\
Change in Population Accessibility (2010-2000) & -1.459 & 0.216 & -6.768 & .000 \\
Number of Stations in 2010 & 16279.939 & 4176.018 & 3.898 & .000 \\
\hline $\mathrm{N}$ & 178 & & & \\
$R^{2}$ & 0.838 & & & \\
\hline
\end{tabular}


eas outside the urban core. Those lines may eventually pay off by channeling development, but there are no guarantees, unlike urban lines which are much more of a sure bet in Beijing. 


\section{References}

Aschauer, D. A. 1989. Is public expenditure productive? Journal of monetary economics, 23(2):177200.

Beijing City Lab. 2014. Bus routes and stops of Beijing.

Block-Schachter, D. and J. Zhao. 2015. Hysteresis \& urban rail. EJTIR, 15(1):78-91.

China Economic Net news. 2014. This year four subway lines opened in Beijing and public transportation travel Proportion reached 48 percent. website. URL http://ce.cn/xwzx/gnsz/gdxw/201404/ 24/t20140424_2716400.shtml.

China Quality Daily. 2014. 2014 beijing bus travel will increase to 48 percent share. URL http: //auto.people.com.cn/n/2014/0311/c153909-24600286.html.

El-Geneidy, A., D. Levinson, E. Diab, G. Boisjoly, D. Verbich, C. Loong, et al. 2016. The cost of equity: Assessing transit accessibility and social disparity using total travel cost. In TRB Annual Proceedings.

Iacono, M. and D. Levinson. 2016. Mutual causality in road network growth and economic development. Transport Policy, 45:209-217.

Ingram, D. R. 1971. The concept of accessibility: a search for an operational form. Regional studies, 5(2):101-107.

King, D. 2011. Developing densely -estimating the effect of subway growth on new york city land uses. the Journal of transport and land use, 4(2):19-32.

Levinson, D. 2008. Density and dispersion: the co-development of land use and rail in london. Journal of Economic Geography, 8:55-77.

Levinson, D., G. D, and B.-E. A. 2015. Accessibility and the choice of network investments in the london underground. Journal of Transport and land use.

Niu, W. Y. 2012. China New-type Urbanization Report. Beijing: Science Press in China.

Vickerman, R. W. 1974. Accessibility, attraction, and potential: a review of some concepts and their use in determining mobility. Environment and Planning A, 6(6):675-691.

Wachs, M. and T. G. Kumagai. 1973. Physical accessibility as a social indicator. Socio-Economic Planning Sciences, 7(5):437-456.

Xie, F. and D. Levinson. 2009. How streetcars shaped suburbanization: a granger causality analysis of land use and transit in the twin cities. Journal of Economic Geography, p. lbp031. 